\title{
Las poéticas explícitas de José Ángel Valente y Antonio Colinas: caracterización de un género
}

\author{
José Ángel Valente and Antonio Colinas' Literary Essays: \\ Characteristics of a Genre
}

\author{
Rocío BADÍA FuMAZ \\ Westfälische Wilhelms - Universität Münster \\ Romanisches Seminar \\ rocio.badia@uni-muenster.de
}

[recibido 31/10/2014, aceptado 26/01/2015]

\section{RESUMEN}

A partir de los textos ensayísticos de contenido literario de José Ángel Valente (Las palabras de la tribu, La experiencia abisal o La piedra y el centro) y de Antonio Colinas (El sentido primero de la palabra poética, Sobre la Vida Nueva o Del pensamiento inspirado), este trabajo propone un intento de caracterización de las poéticas explícitas a partir de sus rasgos necesarios y sus rasgos prototípicos.

PALABRAS ClaVE: Poética explícita, autopoética, ensayo literario, José Ángel Valente, Antonio Colinas.

\section{RESUMO}

A partir dos textos ensaísticos de contido literario de José Ángel Valente (Las palabras de la tribu, La experiencia abisal ou La piedra y el centro) e de Antonio Colinas (El sentido primero de la palabra poética, Sobre la Vida Nueva ou Del pensamiento inspirado), este traballo propón un intento de caracterización das poéticas explícitas a partir dos seus trazos necesarios e dos seus trazos prototípicos.

PALABRas CHaVE: Poética explícita, autopoética, ensaio literario, José Ángel Valente, Antonio Colinas.

\section{ABSTRACT}

Based on the literary essays by José Ángel Valente (Las palabras de la tribu, La experiencia abisal or La piedra y el centro) and Antonio Colinas (El sentido primero de la palabra poética, Sobre la Vida Nueva or Del pensamiento inspirado), this paper aims to describe the poetics written by these poets through their primary and secondary features. KEY wORDS: Poetics, autopoetics, literary essay, José Ángel Valente, Antonio Colinas.

Badía Fumaz, R. (2015): "Las poéticas explícitas de José Ángel Valente y Antonio Colinas: caracterización de un género", Madrygal (Madr.), 18, Núm. Especial: 161-170.

SUMARIO: 1. Introducción. 2. El siglo XX como siglo de las poéticas. 3. Vacilación terminológica. 4. Rasgos necesarios o primarios. 5. Rasgos prototípicos o secundarios. 6. Otros rasgos. 7. Su inclusión en los Estudios Literarios. 8. Referencias bibliográficas. 


\section{INTRODUCCIÓN}

Tanto José Ángel Valente como Antonio Colinas, desde su ámbito geográfico del noroeste español, son autores de una reconocida y consolidada trayectoria poética. No obstante, la extensión de su labor creadora se extiende en ambos casos más allá de los límites de la literatura, siendo ambos activos representantes del panorama ensayístico español contemporáneo. Esta labor ensayística, más estudiada en el caso de las obras de José Ángel Valente, si bien Antonio Colinas cuenta también con entusiastas lectores, es la que vamos a abordar en el presente trabajo.

Dentro del género del ensayo, hemos preferido por tanto aquellos textos que ahondan en la temática literaria. Pretendemos no sólo su análisis sino la elaboración de una caracterización que nos permita reconocer las poéticas explícitas como un tipo de texto particular a partir de los ejemplos concretos de los autores escogidos.

Para ello, dentro de la obra ensayística de Valente hemos seleccionado por su temática literaria Las palabras de la tribu (1971), La piedra y el centro (1982), Variaciones sobre el pájaro y la red (1991), Notas de un simulador (1991), así como las obras póstumas Elogio del calígrafo y La experiencia abisal, que ven la luz en los años 2002 y 2004 respectivamente. Las obras de Antonio Colinas que hemos escogido son El sentido primero de la palabra poética (1989), Sobre la Vida Nueva (1996), Del pensamiento inspirado I y II, (2001), Un tiempo que no pasa (2009), Tres tratados de armonía (2009) y Nuevos ensayos en libertad (2011). Hemos dejado fuera de nuestro análisis aquellos volúmenes ensayísticos de ambos autores que se alejan del tema literario, por ejemplo Elogio del calígrafo, de José Ángel Valente, o La simiente enterrada, de Antonio Colinas.

\section{EL SIGLO XX COMO SIGLO DE LAS POÉTICAS}

Numerosos factores llevan a que en el siglo XX las poéticas explícitas hayan tenido un florecimiento especial. El siglo XX ve cómo la individualidad particular del hombre se resalta, lo que lleva a que el autor se erija en una posición más preeminente de la que hasta ahora ha tenido. Esa preeminencia no tiene por qué llevar aparejado un mayor poder o reconocimiento; sin embargo, sí trae consigo mayor visibilidad, tanto externa como interna, en tanto que el propio autor también va a querer destacarse en su individualidad, lo que, para Gianni Vattimo, crea las condiciones que permiten el éxito de las poéticas de autor como textos paralelos a la obra literaria de cada autor.

En su artículo "Vocación ontológica de las poéticas del siglo XX", Vattimo propone la necesidad de auto-justificación del artista como una razón poderosa para el éxito de este tipo de textos donde la teoría sustituye a la práctica (1993: 51). Su origen, señala el filósofo italiano, puede rastrearse ya en las últimas décadas del siglo XIX, si bien va a destacar el siglo XX como "el siglo de las poéticas" por el lugar que van a ocupar en el panorama artístico (Vattimo 1993: 47).

La preeminencia de lo programático, en ocasiones incluso en sustitución de la obra artística, la importancia de la idea sobre la forma en las últimas corrientes artísticas, nos llevaría a reflexionar sobre la cuestión del lugar del artista, "su condición problemática en el mundo" (Vattimo 1993: 53) que derivará en la voluntad de auto-justificación señalada más arriba.

Paralelamente, el surgimiento de los manifiestos literarios y su evolución durante el siglo XX nos permite seguir ahondando en las condiciones que llevan al éxito de las poéticas explícitas en nuestros días. Como señala Cristina Jarillot en su obra Manifiesto y vanguardia, el manifiesto progresivamente se va desprendiendo de su función primaria de protesta colectiva, debido al "panorama literario atomizado" (2010: 141) que impide una presentación colectiva de ideas. Surge, en consecuencia, el cauce individual en correspondencia con cada voz individual, permitiendo ese florecimiento de las poéticas explícitas que sólo puede darse cuando la individualidad, no la colectividad, está realzada. Los manifiestos, cuya función terminó por ser la defensa de una 
forma y una idea de la creación, van a ser entonces sustituidos por los textos particulares de autor desde su individualidad, lo que va a permitir entender muchos de los rasgos que encontraremos en este tipo de textos.

La activa publicación de poéticas explícitas o poéticas de autor se constata en España por lo menos desde mitad del siglo XX. Los cauces editoriales, en buena medida, contribuyeron a su éxito favoreciendo cierto tipo de antología poética donde cada poeta incluido debía acompañar sus textos de una "Poética", es decir, de un texto donde se explicara su idea de la creación literaria. Algunos ejemplos de estas antologías en las décadas de los 60 y 80 dan buena cuenta de la dimensión del fenómeno: señalemos, por ejemplo, las de Antonio Molina, Poesía cotidiana (1966); José Batlló, Antología de la nueva poesía española (1968) y Poetas españoles postcontemporáneos (1974); Antonio Hernández, La poética del 50 (1978); Leopoldo de Luis, Poesía social (1965); José María Castellet, Nueve novísimos poetas (1970); o Concepción García Moral y Rosa María Pereda, Joven poesía española (1979). Puede verse, por tanto, como el éxito de las poéticas explícitas no responde sólo a la voluntad del individuo sino también a las ocasiones numerosas donde los poetas eran requeridos para explicitar su pensamiento literario.

Por otra parte, y como dinamizador de esta moda de las poéticas, encontramos las respectivas y usuales disputas literarias del momento (conocimiento frente a comunicación, poesía social, irrupción de los novísimos, por citar algunos momentos álgidos) que favorecen la condensación de la opinión personal en forma de breves textos que definen la producción propia y su eventual vinculación con una corriente particular.

La activa publicación de volúmenes completos dedicados a este tipo de texto por parte de los autores literarios, que, como hemos visto en los ejemplos de Colinas y Valente, no es menor, también nos habla de la existencia de un público lector que reclama o acoge positivamente el género. De igual modo, la atención de los estudiosos de la literatura también se ha dirigido, si bien recientemente, hacia este tipo de textos autorreflexivos, como vemos en artículos de tipo bibliográfico como el de Miguel Ángel Olmos titulado "La poesía según los poetas: repertorio de libros de teoría y crítica literarias de poetas españoles contemporáneos (1975-1990)" o en la organización de congresos como el que dio como fruto el volumen editado por Victorino Polo García, Literatura, pensamiento y libertad, que recoge las intervenciones de diversos autores, entre ellos Antonio Colinas, sobre su propia creación literaria.

\section{VACILACIÓN TERMINOLÓGICA}

Poco estudiadas las poéticas explícitas como tipo de texto, encontramos una vacilación patente incluso en la elección del término mediante el cual nos referimos a ellas. Si hasta este momento hemos estado hablando indistintamente de poéticas explícitas o poéticas de autor, la vacilación terminológica a la que nos referimos hace que los términos se multipliquen, encontrando numerosas etiquetas para referirnos al mismo tipo de texto.

Desde un primer momento, el término más extendido y que con más frecuencia encontraremos incluso en la bibliografía crítica, "poética" a secas, se nos antoja insuficiente en tanto que está abierto a múltiples significados diversos ${ }^{1}$. El propio Vattimo cae en esta vacilación, utilizando el término "poética" de una forma no restrictiva, de modo que, si bien excluye acertadamente de su análisis las poéticas académicas o universalistas, se refiere también a los manifiestos e incluso a las

${ }^{1}$ Todorov, en su Diccionario enciclopédico de las ciencias del lenguaje, evita incluir la acepción que nos interesa en nuestro estudio. Para él, el término "poética" designa únicamente "1) toda teoría interna de la literatura; 2) la elección hecha por un autor entre todas las posibilidades (en el orden de la temática, de la composición, del estilo, etc.) literarias: 'la poética de Hugo'; 3) los códigos normativos construidos por una escuela literaria, conjunto de reglas prácticas cuyo empleo se hace obligatorio" (1998: 98). 
corrientes artísticas con ese término (Vattimo 1993: 65-66). Incluso Pedro Provencio, que penetrantemente distingue las poéticas explícitas de la masa de reflexiones sobre el hecho literario en sus dos volúmenes Poéticas españolas contemporáneas. La generación del 50 y Poéticas españolas contemporáneas. La generación del 70, utiliza el término "poética" pese a su escasa funcionalidad.

Pilar Rubio Montaner nos ofrece la etiqueta de "poéticas de autor" (1990), que se alterna por parte de autores de ámbito francófono con la de "poéticas de poeta" (Demers et al. 1993) para hacer explícito el carácter literario de su emisor, lo que viene a poner de relieve, como veremos en seguida, uno de los rasgos constitutivos de este tipo de textos. Otro tipo de matización da lugar al término "pragmática de poeta" (Demers 1994: 9) para incidir en la fundamentación práctica sobre la que se elabora el texto; ese mismo aspecto lo busca poner de relieve René Passeron en su reivindicación de la importancia de lo que él denomina poïétique frente a poétique, siguiendo la estela de Paul Valèry, e incidiendo en el proceso de la creación.

La reflexividad entre el texto y el autor es el rasgo que destaca la etiqueta propuesta por Arturo Casas, "autopoética" recepción en el ámbito gallego y entre los estudiosos hispanoamericanos.

Como resultado de la oposición entre las poéticas académicas y las poéticas individuales de cada autor, Adriana de Teresa (2002) aborda su estudio oponiendo las etiquetas de "poética particular" frente a "poética universalista", si bien, en nuestra opinión, se oscurece con ello la particularidad del autor.

En cambio, el uso de la etiqueta "poéticas explícitas" (ver por ejemplo Domínguez Caparrós 2001) en su oposición a "poéticas implícitas" permite, siempre que se sea consciente del significado del último término, evitar este problema y enraizar con una terminología ya consolidada ${ }^{3}$. Es por ello que es la etiqueta que preferimos y utilizamos en nuestro trabajo, si bien, al ser una terminología poco consolidada, en ocasiones se acude a otras etiquetas por razones de claridad.

\section{RASGOS NECESARIOS O PRIMARIOS}

Consideramos como rasgos necesarios para reconocer un texto como poética explícita la no anonimia del texto, la coincidencia de sujeto y objeto y el carácter ensayístico del texto.

Dado que las poéticas explícitas surgen habitualmente de forma posterior a la producción literaria del autor en cuestión a partir del éxito conseguido en esta última ocupación, entendemos que las poéticas explícitas fundamentan su interés en la vinculación de ese texto ensayístico con el nombre de un autor literario ya reconocido. Por ello, la existencia de un autor de renombre y la imposibilidad de la anonimia son características necesarias en este tipo de textos.

El nombre del emisor de una poética de autor es, entonces, imprescindible. Una poética de autor anónima no tiene sentido, al contrario de los manifiestos, pues está enclavada en una radical individualidad (no pensamiento de grupo, como en manifiestos o en poéticas de escuelas) y referencialidad hacia la propia práctica literaria. A esto se añade el argumento de autoridad: nos fiamos de lo que dice por quién lo dice, pues la autoridad emana de la persona, no sólo de los argumentos.

Esta vinculación tan evidente del texto con la condición del autor genera una escritura desde el yo, que privilegia en consecuencia un uso de la primera persona y de partículas deícticas mayor que en otro tipo de ensayos de carácter literario. Por tanto, aparecen a menudo determinantes y pronombres personales

\footnotetext{
${ }^{2}$ Quiero agradecer a Martín Veiga el haberme llamado la atención en este punto sobre el término "autopoética" utilizado por Arturo Casas, referencia que yo desconocía.

${ }^{3}$ De hecho, la poética explícita no sería sino, como indica su nombre, la explicitación de la poética implícita que podemos abstraer de la obra del autor.
} 
de primera persona, así como una focalización particular desde la que se escribe. Antonio Colinas se refiere a menudo a esta individualidad del punto de vista, reconociendo el carácter particular de su pensamiento, pero también José Ángel Valente, con menor tendencia a la personalización en su discurso, bascula entre la tercera persona y la primera:

En el momento de la creación poética lo único dado es la experiencia en su particular unicidad (objeto específico del poema). El poeta no opera sobre un conocimiento previo del material de la experiencia, sino que ese conocimiento se produce en el mismo proceso creador y es, a mi modo de ver, el elemento en que consiste primariamente lo que llamamos 'creación poética'. (Valente 2008: 42)

En el ejemplo anterior queda claro el esfuerzo que la visión del poeta debe llevar a cabo para hablar de una generalidad ("el poeta") de la que el autor forma parte; por tanto, la visión externa e interna se conjugan, al coincidir lo investigado con el investigador.

Esta cualidad de ser el autor a la vez sujeto y objeto de estudio la destaca Adriana de Teresa en su artículo "Poéticas particulares y universalistas" (2002: 185), y se convierte en el segundo rasgo necesario para caracterizar las poéticas explícitas. Que el poeta sea a la vez el autor y el objeto de la reflexión introduce una restricción temática para este tipo de textos. Desde el punto de vista del contenido, las poéticas explícitas requieren una temática literaria, usualmente centrada en la reflexión sobre la propia poesía o sobre el proceso de creación, si bien sus cauces formales serán, como veremos, variadísimos.

Por último, consideramos un tercer rasgo característico, la prosa, como necesario, dejando de lado textos de contenido literario formalizados en verso, como las artes poéticas, por considerarlas dentro del conjunto de textos literario-artísticos, y no de carácter ensayístico como los que abordamos aquí.

\section{RASGOS PROTOTÍPICOS O SECUN- DARIOS}

Dando por sentada la concurrencia de estos tres rasgos, otros aspectos caracterizan las poéticas explícitas, si bien, pese a ser usuales, no son necesarios para caracterizar como tal este tipo de texto y no pueden por tanto ser considerados como primarios, pues su ausencia no implica un cambio de tipo de texto como si lo hacen los rasgos anteriores.

Frente a las poéticas universalistas, se constata la ausencia de un metalenguaje o lenguaje formal, aspecto compartido por todo el género ensayístico, frente al discurso de tipo científico que se caracteriza por la utilización de ese metalenguaje (Aullón 1987: 22-23).

Por otra parte, las peculiaridades editoriales de este tipo de textos nos hablan de una pluralidad de cauces de difusión. Antologías poéticas, medios de comunicación escritos, conferencias, columnas periodísticas, artículos, etc., son las vías primeras de aparición de las poéticas explícitas. No obstante, otra forma habitual de aparición, o reaparición, de estas composiciones se conjuga con la anterior, bajo la forma de recopilaciones que recogen la producción dispersa del autor. Las obras estudiadas de José Ángel Valente y Antonio Colinas responden a estos patrones de difusión, pues los ejemplos mencionados al comienzo de nuestro trabajo son todos recopilaciones o antologías de textos, publicados o no, aparecidos con anterioridad en diferentes medios o escenarios ${ }^{4}$. Esta apertura de las poéticas explícitas hacia espacios editoriales no habituales del ensayo literario de autor común conllevará una apertura temática mayor y una

${ }^{4}$ Es de notar la colaboración que tanto el poeta ourensano como el bañezano llevan a cabo con publicaciones escritas como El País, Diario 16, ABC o El Mundo, y otros medios regionales como La voz de Galicia, Faro de Vigo, La Región o revistas como Unión Libre (Rodríguez Fer 2008: 17-18) en el caso del primero, y en Los cuadernos del Norte, La Crónica 16 de León o El Adelanto Bañezano, por no incidir en las revistas más clásicas como Revista de Occidente o Cuadernos Hispanoamericanos. 
adaptación del texto a su cauce de difusión, características que se mantienen en los volúmenes recopilatorios.

En correspondencia, las poéticas explícitas se formulan bajo una diversidad de formas muy amplia. Esta formalización tan diversa, que ocupa diferentes géneros discursivos, nos parece el principal escollo que ha dificultado la caracterización de estos textos. Pese a que en José Ángel Valente los textos adoptan una forma más homogénea, habitualmente presentados como artículos, Sánchez Robayna incluye entre sus textos ensayísticos notas juveniles y cartas al director, incluso textos difundidos oralmente en origen, como sus "Palabras en el acto de investidura como Doctor Honoris Causa" o la conversación "El arte como vacío. Conversación con Eduardo Chillida" entre el poeta, el escultor y Francisco Calvo Serraller (Valente 2008: 555-571).

La diversidad genérica de las poéticas explícitas de Colinas es, por el contrario, muy amplia, pudiendo encontrar en los volúmenes señalados al comienzo de nuestro trabajo reseñas, epístolas, prólogos a obras propias y a obras ajenas, epílogos, poéticas que antecedieron a poemas en antologías, artículos, columnas periodísticas, respuestas a cuestionarios, entrevistas o decálogos. Variedad formal que no anula, en nuestra opinión, el carácter de poética explícita de los textos o de fragmentos de los mismos.

Por otra parte, como mencionábamos en la introducción de nuestro trabajo, frente a la Poética tradicional o a los manifiestos, de carácter más programático, las poéticas explícitas aparecen a posteriori de la obra literaria; usualmente ahondan en lo ya dicho o en lo que se está diciendo.
Este carácter no prescriptivo, pese a la voluntad explicativa o de conocimiento que origina el texto, es visible también en la voluntad de provisionalidad con la que el poeta aborda su escritura. Frente a la explicación definitiva y universal, las poéticas explícitas se reconocen en esa sujeción al momento de la composición y a la individualidad de su autor, a la que no se renuncia. Colinas incide en este aspecto en numerosas ocasiones ("seguramente, el poeta ha escrito tantas Poéticas como años de creación ha habido en su vida", 2008: 135136), si bien en el caso de los autores que nos ocupan ya sólo la sucesiva y permanente publicación de poéticas explícitas justifica esta postura en la práctica. Ese proceso de reescritura del pensamiento lo va a destacar Valente en su "Nota preliminar" a Las palabras de la tribu, señalando que "los ensayos recogidos en el presente libro son resultado de un proceso de escritura continua que, en muchos casos, ha obligado a dar de los trabajos ya publicados una nueva versión" (2008: 37).

Si bien los cauces de difusión originarios parecen favorecer la brevedad de los textos, incluso en el caso de contar con apoyo editorial suficiente las poéticas explícitas tienden a la brevedad en la forma. Todos los volúmenes de contenido literario de Valente y de Colinas son recopilaciones de textos breves; no encontramos un volumen compuesto por un único trabajo extenso, al estilo de El arco y la lira de Octavio Paz con quien Pedro Provencio compara a Valente ${ }^{5}$, sino que acogen textos con origen diverso tanto en tiempo como en motivación. Este aparente desorden en la formación de la obra se ve compensado por la coherencia temática que emana de la afinidad del contenido, aspecto resaltado por ambos autores $^{6}$. Sin embargo, este fenómeno da lugar

5 "La poética de Valente, en su estado actual - que no hay que considerar definitivo-, es una de las más estructuradas de la poesía española de nuestro siglo. En nuestra lengua, sólo Octavio Paz ha realizado una labor de tan largo alcance" (Provencio 1988a: 94).

6 "La unidad de un libro puede ser la intencionalmente buscada desde un esquema de formulación previa o la generada por la natural o casi orgánica asociación de sus núcleos temáticos. Sería más bien esta segunda perspectiva la que permitiría percibir la posible unidad de fondo de las páginas que siguen" (Valente 2008: 37), y “este libro tiene para mí -tanto en el sentido global como en su inconcreción- el verdadero carácter de una Poética” (Colinas 2008: 9). 
a repeticiones y redundancias ${ }^{7}$, que parecen ser frecuentes en el conjunto de poéticas explícitas de un autor, sobre todo cuando éstos son fecundos.

El carácter fragmentario de las poéticas explícitas resalta su breve extensión, pues como señala Arturo Casas una poética explícita puede ser, incluso, un fragmento de un texto más amplio, fragmentos, por ejemplo de una autobiografía o una carta (Casas 1999: 214). Este criterio de Casas nos permite incluir dentro de las poéticas explícitas la diversidad de géneros que hemos mencionado con anterioridad.

\section{OTROS RASGOS}

Otros rasgos frecuentes que, sin embargo, contribuyen menos a definir el tipo de texto, pueden ser la coloquialidad ("[1]eí y comenté en una ocasión los poemas de Juan de la Cruz a las monjas del monasterio de Carmelitas Descalzas de Ibiza (sí, no leen ustedes mal, de Ibiza, una de las últimas fundaciones)", Colinas 2001a: 78), la anécdota ("En este París que el viento frío de noviembre barre a ráfagas, salgo a buscar, bajo el tapiz espeso de las hojas caídas, fragmentos de mi vida", Valente 2008: 700) o la abundancia de deícticos, rasgos que en nuestra opinión tienen su origen en una voluntad comunicativa o de acercamiento al receptor por parte del poeta.

Por otro lado, otro rasgo característico pero no necesario es la literariedad de ciertos ejemplos. Esta literariedad la encontramos fundamentalmente en los Tres tratados de armonía de Colinas y en Notas de un simulador de Valente. Señala el primero respecto al género de su obra:

¿Qué había escrito yo? ¿Poesía en prosa, pensamientos, aforismos, páginas de un diario, simples prosas? Era difícil una definición concreta, pues cada texto gozaba, en cierta medida, de todos esos géneros. Por eso, yo me decidí a definirlos como contemplaciones. Contemplar es vivir; contemplar es ser desde la consciencia; contemplar es crear. (2001b: 48)

La indefinición genérica reconocida por el autor desde el momento de la concepción de la obra se corresponde con la percepción del lector, que encuentra en dichas obras rasgos que las sitúan entre el polo literario y el polo ensayístico. El carácter fragmentario de Notas de un simulador, por ejemplo, mueve a Stefano Pradel a definir el texto como un "destilado de reflexión metapoética, territorio intersticial y puente entre la amplia labor ensayística de Valente y su escritura lírica" (2013: 2). Sin embargo, el carácter literario de las poéticas explícitas se percibe en el resto de su producción: Domínguez Rey nos presenta en Valente el "tránsito de la poesía a la prosa más o menos poética" y cómo "amplía este recurso a los mismos ensayos de poética, según podemos advertir en capítulos o párrafos de Las palabras de la tribu o en La piedra y el centro" (2002: 85).

Al reflexionar sobre los artículos que conforman Del pensamiento inspirado, Colinas destaca ese mismo aspecto transgenérico:

cuando hablo de pensamiento inspirado también me estoy refiriendo a un tipo de artículo o ensayo que rompe con el férreo dogmatismo de los géneros; es decir, que participa también de las características de otros géneros, como la poesía. Hay, pues, una base de raíz poética en casi todos los textos que el lector va a leer. (2001a: 8)

No está de más señalar que ese carácter literario parece inherente a la actividad poética desarrollada de forma paralela por los autores. Sin embargo, en nuestra opinión parece responder a una necesidad superior, la de superar los límites de la individualidad y provisionalidad intrínseca que los autores reconocen en las poéticas explícitas. Por ello, éstas tienen un germen de eternidad no en su contenido informativo sino en el poso literario que puedan contener.

\footnotetext{
${ }^{7}$ Ver por ejemplo en la declaración de Sánchez Robayna sobre el criterio de edición de los ensayos de Valente en sus Obras Completas (2008: 28-29), o en la reiterada consideración de la poesía como fruto o como producto en las obras de Antonio Colinas.
} 
7. SU INCLUSIÓN EN LOS ESTUDIOS LITERARIOS

Al margen de la comprensible reivindicación de los propios autores ${ }^{8}$, la necesidad de incluir las poéticas explícitas no sólo dentro de los estudios críticos sobre autores particulares sino como parte de los estudios de Teoría de la Literatura ha sido resaltada con vehemencia por Pilar Rubio Montaner en su artículo "Sobre la necesaria integración de las poéticas de autor en la teoría de la literatura" (1990), sobre todo en su posible contribución al análisis del fenómeno de la creación poética.

No obstante, la llamada de Rubio ha sido sólo parcialmente atendida, debido por una parte al desinterés de la comunidad científica en el tema y, por otra, a los problemas que genera trabajar con este tipo de textos ${ }^{9}$.

La ausencia, por ejemplo, de cierta vocación científica, sistemática, en las poéticas explícitas supone un escollo para el teórico de la literatura ${ }^{10}$. De igual modo, María Rosal Nadales en su tesis doctoral "Poesía y poéticas en las escritoras actuales (1970-2005)" (2006), se plantea la fiabilidad de unos textos cuyo emisor está habitualmente desdoblado en, por lo menos, un yo biográfico y un yo literario:

Y sobre todo, ¿son de fiar las poéticas?, ¿lo que se expresa en ellas responde a una cierta "verdad" o es una construcción más tan artificiosa como cualquier poema en la que las autoras no hacen sino construir otro sujeto poético pensante que muestra otra más de las múltiples máscaras? (2006: 417)

Esa imposibilidad de verificar la voluntad del autor se ve reforzada por la permanen- te aparición de poéticas explícitas en el ámbito español de tipo paródico o lúdico (por ejemplo las poéticas de José María Álvarez o Guillermo Carnero para la antología Nueve novísimos poetas), que mueven a Pedro Provencio a cuestionarse el interés de este tipo de textos:

Pero ¿realmente tienen interés teórico las poéticas redactadas, con frecuencia, a vuelapluma, si no a regañadientes? ¿Conceden los poetas verdadera importancia a estos textos en el conjunto de su obra? ¿Corresponden estas poéticas a la poética implícita en los poemas de cada autor? ¿Tienen características comunes en diferentes autores, de manera que puedan ser admitidas en conjunto como objeto de estudio global? (1988: 10)

Manuela Romo, en su artículo "Teorías implícitas y creatividad artística" (1998) sugiere que el papel de las poéticas explícitas puede ser relevante en su relación con la actividad poética, debido a que "la búsqueda de consonancia cognitiva, a veces, nos exige reestructurar el pensamiento y cambiar la conducta. Hay ocasiones en que no se puede preservar la teoría por la existencia de conflictos repetidos con la experiencia" (Romo 1998: 13). La práctica poética, por tanto, condiciona la reformulación del pensamiento poético llevando a una poética explícita diferente. Sin embargo, esta búsqueda de la reducción de la disonancia cognitiva puede funcionar en el sentido contrario, alterándose la práctica poética para adaptarla a lo proclamado en el texto teórico previo.

Como vemos, la inclusión de las poéticas explícitas en la Teoría de la Literatura debe tener en cuenta diversas cuestiones

\footnotetext{
8 “Es muy sabido: los que escribimos poemas somos los primeros en hacernos la misma pregunta que se puede hacer la gente corriente, la pregunta sobre la posible razón de ser de la poesía" (Gimferrer 1985: $143)$.

9 José María Pozuelo Yvancos sí incluye en su volumen Las ideas literarias (1214-2010) tanto las aportaciones de filólogos como de autores literarios, dedicando un espacio a los ensayos de contenido literario de José Ángel Valente.

${ }^{10}$ Colinas se refiere a esta cuestión en su artículo "La carta que no envié a María Zambrano" describiendo un texto suyo como "sumamente subjetivo y, en consecuencia -dirán algunos- de dudosa categoría intelectual" (2008: 295).
} 
problemáticas, si bien permitiría completar un espacio hasta ahora poco frecuentado, como es el de la reflexión sobre la creación literaria, así como profundizar en las relaciones entre pensamiento literario y actividad literaria en el seno de cada autor.
Por lo demás, la riqueza formal y de contenido de las poéticas explícitas parece reclamar una atención mayor acerca de sus elementos constitutivos, y no sólo una consideración subsidiaria a la hora de iluminar puntos oscuros en la obra poética particular de cada autor.

\section{REFERENCIAS BIBLIOGRÁFICAS}

CASAS, Arturo (2000): "La función autopoética y el problema de la productividad histórica", en J. Romera Castillo y F. Gutiérrez Carbajo (eds.), Poesía histórica y (auto)biográfica (19751999). Madrid: Visor, pp. 209-218.

Colinas, Antonio (1996): Sobre la Vida Nueva. Oviedo: Nobel.

(2001a): Del pensamiento inspirado I. Valladolid: Junta de Castilla y León.

(2001b): Del pensamiento inspirado II. Valladolid: Junta de Castilla y León.

(2008): El sentido primero de la palabra poética. Madrid: FCE.

(2009a): Tres tratados de armonía. Barcelona: Tusquets.

- (2009b): Un tiempo que no pasa. Valladolid: Universidad de Valladolid.

(2011): Nuevos ensayos en libertad. Sevilla: La isla de Siltolá.

Demers, Jeanne, Yves Laroche y Pierre Popovic (1993): La poétique de poète (volumen monográfico de Études françaises, 29/3).

Demers, Jeanne (1993): “Presentation. En liberté, la poétique”, Études françaises 29/3, pp. 7-15.

Domínguez CAPARRós, José (2001): “Comunicación literaria y poética explícita”, en J. Domínguez Caparrós, Estudios de Teoría Literaria. Valencia: Tirant lo Blanch, pp. 51-66.

Domínguez Rey, Antonio (2002): Limos del verbo (José Ángel Valente). Madrid: Verbum.

Gimferrer, Pere (1985): “El porqué de la poesía”, en Segundo dietari. Seix Barral: Barcelona, pp. 143-144

JARILlot Rodal, Cristina (2010): Manifiesto y vanguardia. Bilbao: Universidad del País Vasco.

Olmos, Miguel Ángel (1991-92): "La poesía según los poetas: repertorio de libros de teoría y crítica literarias de poetas españoles contemporáneos (1975-1990)", Dicenda 10, pp. 169-173.

Polo GarcíA, Victorino (ed.) (1990): Literatura, pensamiento y libertad. Murcia: Universidad de Murcia.

Pozuelo Yvancos, José María (2011): Las ideas literarias (1214-2010). Barcelona: Crítica.

Pradel, Stefano (2013): "Epifanías al margen. Notas de un simulador, de J..A. Valente”, Orillas. Rivista d'Ispanistica 2, pp. 1-11.

Provencio, Pedro (1988a): Poéticas españolas contemporáneas. La generación del 50. Madrid: Hiperión.

(1988b): Poéticas españolas contemporáneas. La generación del 70. Madrid: Hiperión.

RodríGuez Fer, Claudio (2008): “Introducción”, en J. A. Valente, Obras completas II. Ensayos. Barcelona: Galaxia Gutenberg, pp. 9-31. 
Romo, Manuela (1998): “Teorías implícitas y creatividad artística”, Arte, individuo y Sociedad 10, pp. 11-28,

Rosal Nadales, María (2006): Poesía y poéticas en las escritoras españolas actuales (19702005). Tesis doctoral. Granada: Universidad de Granada.

Rubio Montaner, Pilar (1990): "Sobre la necesaria integración de las poéticas de autor en la teoría de la literatura", Castilla. Estudios de literatura 15, pp. 183-197.

SÁnchez Robayna, Andrés (2008): “Sobre la presente edición”, en J. A. Valente, Obras completas II. Ensayos. Barcelona: Galaxia Gutenberg, pp. 27-31.

Teresa OchoA, Adriana de (2002): "Poéticas particulares y universalistas", Anuario de Letras Modernas 10, pp. 183-192.

Todorov, Tzvetan (1998): "Poética", en O. Ducrot y T. Todorov, Diccionario enciclopédico de las ciencias del lenguaje. México: Siglo XXI, pp. 98-103.

VAlente, José Ángel (1971): Las palabras de la tribu. Madrid: Siglo XXI. (1982): La piedra y el centro. Madrid: Taurus. (1991a): Notas de un simulador. Madrid: La Palma. (1991b): Variaciones sobre el pájaro y la red. Barcelona: Tusquets. (2002): Elogio del calígrafo. Barcelona: Galaxia Gutenberg. (2004): La experiencia abisal. Barcelona: Galaxia Gutenberg. (2008): Obras completas II. Barcelona: Galaxia Gutenberg.

VAtтimo, Gianni (1993): Poesía y ontología. Valencia: Universidad de Valencia. 